\title{
Papers
}

\section{Perinatal outcome of singletons and twins after assisted conception: a systematic review of controlled studies}

Frans M Helmerhorst, Denise A M Perquin, Diane Donker, Marc J N C Keirse

\begin{abstract}
Objective To compare the perinatal outcome of singleton and twin pregnancies between natural and assisted conceptions. Design Systematic review of controlled studies published 1985-2002.

Studies reviewed 25 studies were included of which 17 had matched and 8 had non-matched controls.

Main outcome measures Very preterm birth, preterm birth, very low birth weight, low birth weight, small for gestational age, caesarean section, admission to neonatal intensive care unit, and perinatal mortality.

Results For singletons, studies with matched controls indicated a relative risk of 3.27 (95\% confidence interval 2.03 to 5.28) for very preterm ( $<32$ weeks) and 2.04 (1.80 to 2.32 ) for preterm $(<37$ weeks) birth in pregnancies after assisted conception. Relative risks were 3.00 (2.07 to 4.36 ) for very low birth weight $(<1500 \mathrm{~g}), 1.70$ (1.50 to 1.92) for low birth weight $(<2500 \mathrm{~g})$, 1.40 (1.15 to 1.71 ) for small for gestational age, 1.54 (1.44 to 1.66) for caesarean section, 1.27 (1.16 to 1.40) for admission to a neonatal intensive care unit, and 1.68 (1.11 to 2.55 ) for perinatal mortality. Results of the non-matched studies were similar. In matched studies of twin gestations, relative risks were 0.95 (0.78 to 1.15$)$ for very preterm birth, 1.07 (1.02 to 1.13$)$ for preterm birth, 0.89 (0.74 to 1.07 ) for very low birth weight, 1.03 (0.99 to 1.08) for low birth weight, 1.27 (0.97 to 1.65) for small for gestational age, 1.21 (1.11 to 1.32) for caesarean section, 1.05 (1.01 to 1.09) for admission to a neonatal intensive care unit, and 0.58 (0.44 to 0.77 ) for perinatal mortality. The non-matched studies mostly showed similar trends.

Conclusions Singleton pregnancies from assisted reproduction have a significantly worse perinatal outcome than non-assisted singleton pregnancies, but this is less so for twin pregnancies. In twin pregnancies, perinatal mortality is about $40 \%$ lower after assisted compared with natural conception.
\end{abstract}

\section{Introduction}

Twenty five years of assisted reproductive technology have not freed it from being a focus of medical, social, and political debate. Throughout this, reproductive technology has stood its ground, predominantly by offering parenthood to people who might not otherwise achieve it. However, issues that followed in its wake, such as surrogacy and pre-implantation diagnosis, have kept the momentum going on what many see as a loaded issue. It may be impossible to forecast where this will lead, but it should be possible to assess objectively whether babies born after assisted conception fare better or worse than those born after natural conception.
This question seems to be answered already by the widespread belief that pregnancy outcome is substantially worse after assisted conception. ${ }^{1-3}$ The difference, however, relates predominantly to the higher frequency of multiple pregnancies. ${ }^{3}$ The first indication that assisted singleton pregnancies may also have poorer outcomes appeared in $1985,{ }^{2}$ but it was not clear how much related to assisted reproduction or to confounders, such as maternal age and parity. Several matched cohort studies have since confirmed these findings. ${ }^{14-8}$ Some studies found an opposite trend, ${ }^{910}$ while most reported differences that were compatible with chance. Moreover, for twin pregnancies the general consensus, with few exceptions, ${ }^{11-13}$ seems to be that assisted twin pregnancies have outcomes that are either similar to or slightly better than those conceived naturally. ${ }^{1}{ }^{14-17}$

We identified all published studies on birth outcomes after assisted conception that distinguished singleton from multiple pregnancies and that incorporated an appropriate control group from the same population. We examined whether there are genuine differences in outcome between assisted and natural conceptions and whether they apply to both singleton and twin pregnancies.

\section{Methods}

We searched Medline, Embase, LILACS, and POPLINE for 1985-2002 with the MESH words perinatal care, fertilization in vitro, and the keywords perinatal outcome, perinatal care, assisted reproduction, and IVF, without language limitation. This search was supplemented with the references of the articles, review articles, and theses.

We selected reports with categorical data on any of the following outcomes: gestational age and weight at birth, caesarean section, perinatal death, and admission to neonatal intensive care. Studies without a control group of natural conceptions or that did not distinguish singleton from multiple pregnancies were excluded. The remaining studies were controlled and we subdivided them into matched and non-matched, depending on the nature of the control group.

All authors read the studies, and at least two authors extracted data separately. Disagreements were resolved in discussion, if necessary after we contacted the original authors. All outcomes, except caesarean section, were expressed per number of infants.

International definitions were followed for preterm $(<37$ weeks), very preterm ( $<32$ weeks), low birth weight $(<2500 \mathrm{~g})$,

Nine tables of detailed results and a list of excluded studies can be found + on bmj.com 
Table 1 Summary of risk of various outcomes in singleton and twin pregnancies after assisted conception compared with those conceived naturally. Figures are relative risk ( $95 \%$ confidence intervals)

\begin{tabular}{|c|c|c|c|c|}
\hline \multirow[b]{2}{*}{ Outcome } & \multicolumn{2}{|c|}{ Singleton births } & \multicolumn{2}{|c|}{ Twin births } \\
\hline & Matched studies & Non-matched studies & Matched studies & Non-matched studies \\
\hline \multicolumn{5}{|l|}{ Gestational age (weeks): } \\
\hline$<32$ & 3.27 (2.03 to 5.28$)$ & Not tested & 0.95 (0.78 to 1.15$)$ & $1.20(0.82$ to 1.78$)$ \\
\hline $32-36$ & 2.05 (1.71 to 2.47 ) & Not tested & 1.07 (1.00 to 1.14$)$ & 0.88 (0.66 to 1.17$)$ \\
\hline$<37$ & 2.04 (1.80 to 2.32$)$ & 1.94 (1.31 to 2.88 ) & $1.07(1.02$ to 1.13$)$ & $0.99(0.80$ to 1.23$)$ \\
\hline \multicolumn{5}{|l|}{ Birth weight $(\mathrm{g})$ : } \\
\hline$<1500$ & 3.00 (2.07 to 4.36$)$ & $1.57(0.21$ to 11.7$)$ & 0.89 (0.74 to 1.07$)$ & 1.46 (1.01 to 2.11$)$ \\
\hline $1500-2499$ & 1.54 (1.30 to 1.82$)$ & 3.28 (2.04 to 5.27 ) & 1.02 (0.97 to 1.08$)$ & 1.05 (0.96 to 1.15$)$ \\
\hline$<2500$ & 1.70 (1.50 to 1.92$)$ & 2.58 (1.80 to 3.68$)$ & 1.03 (0.99 to 1.08$)$ & $1.12(1.06$ to 1.19$)$ \\
\hline Small for gestational age & $1.40(1.15$ to 1.71$)$ & 1.46 (0.98 to 2.15$)$ & 1.27 (0.97 to 1.65$)$ & 0.93 (0.73 to 1.18$)$ \\
\hline Caesarean section & 1.54 (1.44 to 1.66$)$ & 2.33 (1.95 to 2.79 ) & 1.21 (1.11 to 1.32$)$ & 1.17 (1.06 to 1.29$)$ \\
\hline Neonatal intensive care unit & $1.27(1.16$ to 1.40$)$ & 1.38 (0.67 to 2.86$)$ & 1.05 (1.01 to 1.09$)$ & 1.26 (1.16 to 1.36$)$ \\
\hline Perinatal mortality & 1.68 (1.11 to 2.55$)$ & 3.77 (1.15 to 12.4$)$ & 0.58 (0.44 to 0.77 ) & 0.84 (0.53 to 1.32$)$ \\
\hline
\end{tabular}

Table 2 Preterm birth in singleton pregnancies after assisted conception compared with matched controls (natural conception)

\begin{tabular}{|c|c|c|c|}
\hline Study & No (\%) assisted & No $(\%)$ natural & $\begin{array}{l}\text { Relative risk }(95 \% \\
\text { CI) }\end{array}$ \\
\hline \multicolumn{4}{|c|}{ Very preterm (<32 weeks) } \\
\hline Dhont et al ${ }^{1 *}$ & $63 / 3048 \quad(2.1)$ & $8 / 3048 \quad(0.3)$ & $7.88(3.78 \text { to } 16.4)^{*}$ \\
\hline Dhont et a $\left.\right|^{9}$ & $4 / 311 \quad(1.3)$ & $18 / 622 \quad(2.9)$ & $0.44(0.15$ to 1.30$)$ \\
\hline Koivurova et al $^{19} \dagger$ & $3 / 153 \quad(2.0)$ & $3 / 287 \quad(1.0)$ & $1.88(0.38$ to 9.18$) \dagger$ \\
\hline Total & $70 / 3512 \quad(2.0)$ & $29 / 3957 \quad(0.7)$ & 3.27 (2.03 to 5.28$)$ \\
\hline \multicolumn{4}{|c|}{ Preterm (<37 weeks) } \\
\hline Dhont et al ${ }^{1 *}$ & $344 / 3048(11.3)$ & $125 / 3048 \quad(4.1)$ & $2.75(2.26 \text { to } 3.36)^{*}$ \\
\hline Dhont et al $\left.\right|^{9}$ & $26 / 311 \quad(8.4)$ & $65 / 622(10.5)$ & 0.80 (0.52 to 1.23$)$ \\
\hline Isaksson et al $^{10}$ & $4 / 69 \quad(5.8)$ & $35 / 345(10.1)$ & $0.57(0.21$ to 1.56$)$ \\
\hline Koivurova et al ${ }^{19} \dagger$ & $13 / 153 \quad(8.5)$ & $16 / 287 \quad(5.6)$ & $1.52(0.75$ to 3.08$) \dagger$ \\
\hline Koudstaal et al ${ }^{8}$ & $46 / 307(15.0)$ & $18 / 307 \quad(5.9)$ & 2.56 (1.52 to 4.30$)$ \\
\hline Nuojua et $\mathrm{al}^{21}$ & $8 / 92 \quad(8.7)$ & $14 / 276 \quad(5.1)$ & $1.71(0.74$ to 3.96$)$ \\
\hline Petersen et al ${ }^{22}$ & $5 / 70 \quad(7.1)$ & $3 / 70 \quad(4.3)$ & $1.67(0.41$ to 6.71$)$ \\
\hline Reubinoff et $\mathrm{al}^{7}$ & $23 / 260 \quad(8.8)$ & $10 / 260 \quad(3.8)$ & $2.30(1.12$ to 4.74$)$ \\
\hline Tallo et $\mathrm{al}^{12}$ & $6 / 62 \quad(9.7)$ & $1 / 62 \quad(1.6)$ & 6.00 (0.74 to 48.4$)$ \\
\hline Tan et $\mathrm{al}^{4}$ & 69/494 (14.0) & $78 / 978 \quad(8.0)$ & 1.75 (1.29 to 2.38$)$ \\
\hline Tanbo et $\mathrm{al}^{5}$ & $53 / 355(14.9)$ & $61 / 643 \quad(9.5)$ & 1.57 (1.12 to 2.22$)$ \\
\hline Verlaenen et al ${ }^{6}$ & $16 / 140(11.4)$ & $2 / 140 \quad(1.4)$ & 8.00 (1.87 to 34.2$)$ \\
\hline Total & $613 / 5361(11.4)$ & $428 / 7038 \quad(6.1)$ & 2.04 (1.80 to 2.32$)$ \\
\hline
\end{tabular}

*Based on additional data obtained from authors.

†Surviving infants only.

very low birth weight $(<1500 \mathrm{~g})$, small for gestational age (birth weight $<10$ th centile for gestation), and perinatal mortality (stillbirths and deaths in first week $\geq 500 \mathrm{~g}$ per 1000 total births $\geq 500 \mathrm{~g}$ ). We used Review Manager (Update Software, Oxford) to calculate relative risks and $95 \%$ confidence intervals.

\section{Results}

Included studies are listed in tables A and B on www.bmj.com. Seventeen (14 matched and three non-matched) dealt with singleton pregnancies and $17 \quad(10$ matched and seven non-matched) with twin pregnancies. The tables show country and years covered by the study, types of assisted conception, number of cases, and type of controls.

Table 1 summarises relative risks of the outcomes in singleton and twin pregnancies after assisted and natural conception. Analyses for preterm birth and perinatal mortality are presented in tables 2-4, with more details and results for other outcomes in web tables C-I (see www.bmj.com). The website also lists the excluded studies with reasons for exclusion.
Table 3 Preterm birth in twin pregnancies after assisted conception compared with matched controls (natural conception)

\begin{tabular}{|c|c|c|c|}
\hline Study & No $(\%)$ assisted & No (\%) natural & $\begin{array}{l}\text { Relative risk }(95 \% \\
\text { CI) }\end{array}$ \\
\hline \multicolumn{4}{|c|}{ Very preterm (<32 weeks) } \\
\hline$\overline{D h o n t}$ et $\mathrm{al}^{1 *}$ & $173 / 2482 \quad(7.0)$ & 178/2482 (7.2) & $0.97(0.79 \text { to } 1.19)^{*}$ \\
\hline Dhont et al ${ }^{9}$ & $16 / 230 \quad(7.0)$ & $12 / 230 \quad(5.2)$ & 1.33 (0.65 to 2.76$)$ \\
\hline Koivurova et al ${ }^{19} \dagger$ & $2 / 103 \quad(1.9)$ & $11 / 103(10.7)$ & $0.18(0.04$ to 0.80$) \dagger$ \\
\hline Total & $191 / 2815 \quad(6.8)$ & $201 / 2815 \quad(7.1)$ & 0.95 (0.78 to 1.15$)$ \\
\hline \multicolumn{4}{|c|}{ Preterm (<37 weeks) } \\
\hline Dhont et al ${ }^{1 \star}$ & 1227/2482 (49.4) & $1184 / 2482(47.7)$ & $1.04(0.98 \text { to } 1.10)^{*}$ \\
\hline Dhont et $\mathrm{al}^{9}$ & $120 / 230(52.2)$ & $98 / 230(42.6)$ & 1.22 (1.01 to 1.49$)$ \\
\hline Isaksson et $\mathrm{al}^{10}$ & $14 / 40(35.0)$ & $82 / 200(41.0)$ & 0.85 (0.54 to 1.34$)$ \\
\hline Koivurova et al ${ }^{19} \dagger$ & $45 / 103(43.7)$ & $45 / 103(43.7)$ & $1.00(0.73$ to 1.36$) \dagger$ \\
\hline Koudstaal et $\mathrm{al}^{13}$ & $98 / 192(51.0)$ & $80 / 192(41.7)$ & 1.23 (0.99 to 1.52$)$ \\
\hline Moise et al ${ }^{11}$ & $24 / 40(60.0)$ & $16 / 80(20.0)$ & 3.00 (1.81 to 4.98$)$ \\
\hline Petersen et $\mathrm{al}^{22}$ & $6 / 32(18.8)$ & $12 / 32(37.5)$ & $0.50(0.21$ to 1.17$)$ \\
\hline Tallo et al ${ }^{12} \dagger$ & 40/68 (58.8) & $25 / 68(36.8)$ & 1.60 (1.11 to 2.32$) \dagger$ \\
\hline Tan et $\mathrm{al}^{4}$ & $146 / 250(58.4)$ & $22 / 42(52.4)$ & $1.11(0.82$ to 1.52$)$ \\
\hline Total & $1720 / 3437(50.0)$ & $1564 / 3429(45.6)$ & 1.07 (1.02 to 1.13$)$ \\
\hline
\end{tabular}

*Based on additional data obtained from the authors.

†Surviving infants only.

\section{Preterm birth}

Very preterm singletons ( $<32$ weeks) were reported in only three studies with a prevalence of $1.3-2.1 \%$ in assisted conceptions and $0.3-2.9 \%$ in natural conceptions, a relative risk of 3.27 (95\% confidence interval 2.03 to 5.28) (table 2). ${ }^{19} 19$ Mildly preterm singletons (32-36 weeks) accounted for 6.5-9.2\% and $3.8-7.6 \%$, respectively, $(2.05,1.71$ to 2.47 ) (see web table C). ${ }^{9}{ }^{19}$ Preterm singletons ( $<37$ weeks) accounted for 5.8-15\% and $1.4-10.5 \%$, respectively (table 2 ). The relative risk in both the 12 matched $^{14-1012} 192122$ and two non-matched ${ }^{2325}$ studies showed a doubling of the risk of preterm birth after assisted conception.

Very preterm twins were reported in three matched studies $^{19}{ }^{19}$ (detailed in table 3) and two non-matched ${ }^{17}{ }^{26}$ studies. After we excluded one study that reported live infants only, ${ }^{19}$ the frequency range was $7.0-10.5 \%$ in assisted conceptions and 4.9$10.7 \%$ in natural conceptions and was not statistically different (see web table D). Mildly preterm twins accounted for 41.7-45.2\% of cases and $33.0-40.5 \%$ of controls in the matched studies (1.07, 1.00 to 1.14$).{ }^{19}{ }^{19}$ Preterm twins differed widely in frequency from $18.8-60.0 \%$ and $20.0-52.4 \%$, respectively. The relative risk was 1.07 (1.02 to 1.13$)$ in the nine matched studies ${ }^{149-13} 1922$ (table 3 ) and 0.99 (0.80 to 1.23 ) in the two non-matched studies (see web table D). ${ }^{173}$ 
Table 4 Perinatal mortality in singleton and twin pregnancies after assisted conception compared with natural conception

\begin{tabular}{|c|c|c|c|}
\hline Study & No $(\% o)$ assisted & No $(\%)$ natural & $\begin{array}{c}\text { Relative risk (95\% } \\
\text { CI) }\end{array}$ \\
\hline \multicolumn{4}{|l|}{ Singletons } \\
\hline \multicolumn{4}{|c|}{ Matched singleton studies: } \\
\hline Dhont et al ${ }^{1 *}$ & $41 / 3048(13.5)$ & $18 / 3048 \quad(5.9)$ & $2.28(1.31 \text { to } 3.96)^{*}$ \\
\hline Dhont et al ${ }^{9}$ & $2 / 311 \quad(6.4)$ & $10 / 622(16.1)$ & 0.40 (0.09 to 1.81$)$ \\
\hline Isaksson et al ${ }^{10}$ & $1 / 69(14.5)$ & $5 / 345 \quad(14.5)$ & 1.00 (0.12 to 8.43$)$ \\
\hline Koudstaal et $\mathrm{al}^{8}$ & $3 / 307 \quad(9.8)$ & $1 / 307 \quad(3.3)$ & 3.00 (0.31 to 28.7$)$ \\
\hline Nuojua et $\mathrm{al}^{21}$ & $1 / 92(10.9)$ & $2 / 276 \quad(7.2)$ & 1.50 (0.14 to 16.4$)$ \\
\hline Reubinoff et al ${ }^{7}$ & $2 / 260 \quad(7.7)$ & $1 / 260 \quad(3.8)$ & 2.00 (0.18 to 21.9$)$ \\
\hline Tanbo et al ${ }^{5}$ & 4/355 (11.3) & $\begin{array}{ll}6 / 643 & (9.3) \\
\end{array}$ & 1.21 (0.34 to 4.25$)$ \\
\hline Verlaenen et al $^{6}$ & $3 / 140(21.4)$ & 2/140 (14.3) & 1.50 (0.25 to 8.84$)$ \\
\hline Total & $57 / 4582(12.4)$ & $45 / 5641 \quad(8.0)$ & 1.68 (1.11 to 2.55 ) \\
\hline \multicolumn{4}{|c|}{ Non-matched singleton studies: } \\
\hline Olivennes et $\mathrm{a}^{25} \dagger$ & $3 / 162(18.5)$ & $25 / 5096 \quad(4.9)$ & 3.77 (1.15 to 12.4$)$ \\
\hline \multicolumn{4}{|l|}{ Twins } \\
\hline \multicolumn{4}{|l|}{ Matched twin studies: } \\
\hline Dhont et al ${ }^{1 *}$ & $61 / 2482(24.6)$ & $82 / 2482 \quad(33.0)$ & $0.74(0.54 \text { to } 1.03)^{*}$ \\
\hline Dhont et al ${ }^{9}$ & $0 / 230$ & $6 / 230 \quad(26.1)$ & 0.08 (0.00 to 1.36$)$ \\
\hline Fitzsimmons et al ${ }^{16}$ & $4 / 112(35.7)$ & $48 / 216(222.2)$ & 0.16 (0.06 to 0.43 ) \\
\hline Isaksson et al| ${ }^{10}$ & $0 / 40$ & $6 / 200 \quad(30.0)$ & 0.38 (0.02 to 6.56$)$ \\
\hline Koudstaal et al ${ }^{13}$ & 3/192 (15.6) & $1 / 192 \quad(5.2)$ & 3.00 (0.31 to 28.6$)$ \\
\hline Tallo et al ${ }^{12}$ & $4 / 72(55.6)$ & $4 / 72 \quad(55.6)$ & 1.00 (0.26 to 3.85$)$ \\
\hline Total & $72 / 3128$ (23.0) & 147/3392 (43.3) & 0.58 (0.44 to 0.77 ) \\
\hline \multicolumn{4}{|c|}{ Non-matched twin studies: } \\
\hline Agustsson et al ${ }^{14}$ & 2/138 (14.5) & 16/906 (17.6) & 0.82 (0.19 to 3.53 ) \\
\hline Lambalk et a ${ }^{28}$ & $18 / 1158$ (15.5) & 16/884 (18.1) & 0.86 (0.44 to 1.67 ) \\
\hline Olivennes et al ${ }^{17}$ & $10 / 144(69.4)$ & $28 / 328 \quad(85.4)$ & 0.81 (0.41 to 1.63 ) \\
\hline Total & $30 / 1440$ (20.8) & $60 / 2118$ (28.3) & 0.84 (0.53 to 1.32$)$ \\
\hline
\end{tabular}

*Early neonatal deaths in this paper are erroneously labelled as early fetal deaths, but they are included in perinatal deaths.

†Two cases lost to follow up.

\section{Birth weight}

Singletons weighing $<1500 \mathrm{~g}$ were reported for six matched studies ${ }^{15691019}$ and one non-matched study. ${ }^{25}$ Frequencies in the matched studies were $1.5-3.9 \%$ for assisted conceptions and 0.3 $2.7 \%$ for natural conceptions with a relative risk of 3.00 (2.07 to 4.36) (see web table E). Singletons weighing $<2500 \mathrm{~g}$ were more common among cases than among controls in both matched $(\mathrm{n}=12)^{1} 4-1012192122$ and non-matched $(\mathrm{n}=2)^{23} 25$ studies. Percentages of low birth weight were $2.9-15.7 \%$ in cases, $0-11.5 \%$ in matched controls, and 3.6-4.8\% in non-matched controls (see web table E).

Twins $<1500 \mathrm{~g}$ accounted for $5.0-25.0 \%$ of cases and $3.8-10.4 \%$ of controls (omitting one study reporting live infants only). ${ }^{19}$ The relative risk was $0.89(0.74$ to 1.07$)$ for the five matched $^{19-1119}$ and 1.46 (1.01 to 2.11) for the two non-matched studies (see web table F) ${ }^{17}{ }^{27}$ Twins $<2500 \mathrm{~g}$ accounted for 37.5$70.6 \%$ and $50.0-98.6 \%$ of cases versus $38.1-58.8 \%$ and $52.5-94.5 \%$ of controls, with relative risks of 1.03 (0.99 to 1.08) and 1.12 (1.06 to 1.19), respectively, in the eight matched studies $^{149-131922}$ and the four non-matched studies. ${ }^{17232627}$

\section{Small for gestational age}

The 12 studies that reported on infants who were small for gestational age applied various reference charts. The frequency in singleton cases and controls was $1.6-16.3 \%$ versus $1.6-13.1 \%$ with a relative risk of 1.40 and 1.46 , respectively, for the six matched $^{4-81220}$ and two non-matched studies (see web table $\mathrm{G}){ }^{23}{ }^{25}$ The four matched ${ }^{411-13}$ and three non-matched ${ }^{17}{ }^{23}{ }^{26}$ twin studies showed no significant difference between assisted and natural conceptions.

\section{Caesarean section}

Rates of caesarean section were significantly higher after assisted than after natural conception (see web table $\mathrm{H}$ ). The effect was more marked for singleton than for twin pregnancies in both matched $^{14-8} 101113182021$ and non-matched studies. ${ }^{141724-27}$

\section{NICU admissions}

Admissions to neonatal intensive care were more common after assisted conception in both matched and non-matched studies, and the difference was larger for singletons $s^{15-7910192123}$ than for twins (see web table I). ${ }^{19-11} 1419232627$

\section{Perinatal mortality}

Perinatal mortality differed widely among studies (table 4). In singleton pregnancies it was significantly higher after assisted than after natural conception in both matched and non-matched studies. All of the difference in the matched studies was accounted for by the study of Dhont et al in 1999, which contributed $67 \%$ of the cases. ${ }^{1}$ Without this study mortality was 10.4 per 1000 for both cases and controls.

Matched twin studies were also dominated by the same study, which contributed $78 \%$ of the cases, ${ }^{1}$ and by another with an extraordinarily high mortality among controls. ${ }^{16}$ However, most twin studies showed a lower mortality after assisted than after natural conception, with a relative risk of 0.58 (0.44 to 0.77$)$ for matched and 0.84 (0.53 to 1.32) for non-matched studies (table 4).

\section{Discussion}

\section{Bias and confounding}

Though assisted conception has had many successes, it seems that resulting singleton pregnancies have a worse outcome compared with naturally conceived singleton pregnancies. We chose to concentrate on birth issues and ignore early pregnancy outcomes, which are prone to ascertainment bias because they are detected more readily after assisted conception. This does not imply that birth outcomes are free from bias. Women with assisted pregnancies differ from other women in many characteristics that influence outcome, including age, parity, and socioeconomic status, ${ }^{12}{ }^{12}$ while subfertility itself also contributes to the difference..$^{29}$ We therefore subdivided studies into those with matched and those with non-matched, population specific controls and placed greater emphasis on the former. These virtually all matched for prominent confounders, such as age and parity, but they varied widely in controlling for other known confounders, such as socioeconomic status, smoking, and pre-existing disease. Although none controlled for all factors that might be important, they are likely to estimate true differences between assisted and natural conceptions better than the population based studies.

Nevertheless, our study uncovered major limitations of the matched cohort approach to differences in perinatal outcome between assisted and natural conceptions. Our summary results are largely dominated by a matched cohort study from Flanders, which contributed $54 \%$ of the cases in the singleton studies and $68 \%$ in the twin studies. ${ }^{1}$ Its authors used three different control groups of singletons to match for various combinations of characteristics. $^{1}$ This led to disparate comparison groups, with perinatal mortality, for example, being 5.2 per 1000 in controls matched for maternal age and infant sex and 12.1 per 1000 in those matched also for parity and gestational age. The validity of matching for gestational age is questionable because gestational age is clearly influenced by assisted conception and affects other outcomes, such as birth weight and mortality. We therefore 
included only the controls matched for maternal age, infant sex, and parity. In another study, controls, but not cases, included several twin to twin transfusions in babies referred for special care. ${ }^{16}$ Similar degrees of arbitrariness may have applied to other matched cohort studies without being apparent from the data.

\section{Risk factors}

Despite these limitations it is clear that the rate of preterm birth in singleton pregnancies after assisted reproduction is twice that seen with natural conceptions. This means that assisted reproduction is as much as a predictor for preterm birth as history of preterm birth..$^{30}$ The effect was larger for very preterm than for mildly preterm births and translated into higher rates of (very) low birth weight, admission to intensive care, and perinatal death. However, not all of these should be attributed to preterm birth as there were also $40 \%$ more infants who were small for gestational age after assisted conception. There is some evidence that factors which influence gestational age at birth also influence weight for gestation, ${ }^{31}$ and assisted conception may belong to the factors that influence both fetal weight and length of gestation.

On the other hand, if small for gestation fetuses are detected, this may prompt intervention that leads to earlier birth thereby contributing to both preterm and low birthweight rates. Unfortunately, we could not distinguish preterm births due to obstetric intervention from spontaneous preterm births. Neither could we ascertain that all singleton pregnancies, especially after assisted conception, were singleton pregnancies from the start rather than what remained after resorption of additional gestational sacs.

\section{Twins}

While the results of the matched and non-matched singleton studies invariably supported each other, this was less so for twin pregnancies. Differences between assisted and natural conceptions were all much smaller than in singleton pregnancies, often with confidence intervals that included unity. This is not due to smaller numbers because the overall sample size for twin studies was $84 \%$ of that of the singleton studies and the confidence intervals were smaller than for singletons.

An added risk, such as assisted conception, may have a marked impact on a low risk singleton pregnancy, but only a small effect on the heavily weighted balance of twin pregnancy. Assisted twin pregnancies may actually start off with a relative advantage over singleton pregnancies. As these studies were conducted when $85 \%$ of cycles of in vitro fertilisation entailed transfer of several embryos, ${ }^{3}{ }^{32}$ most births must have originated from the transfer of more than one embryo. Development of two rather than one may reflect an implantation advantage that accounts for the smaller difference in outcome between assisted and natural conceptions in twins than in singletons. Chorionicity certainly plays a part too. Dichorionic pregnancies fare better than monochorionic pregnancies and the latter account for $5-7 \%$ of assisted compared with $30 \%$ of natural twin pregnancies. ${ }^{33}$ This effect was not obvious, though, in the studies that controlled for zygosity. ${ }^{11}{ }^{13}$ Earlier detection of twins with adaptation of antenatal care has been named as another factor, ${ }^{17}$ but it is unclear what adaptations would significantly advantage assisted over natural twin pregnancies. However, none of this seems to explain the lower perinatal death rate in assisted than in natural twin pregnancies, especially as the other outcomes provide no indication how this might be mediated.

\section{What is already known on this topic}

There is a widespread belief that pregnancy outcome is worse after assisted than after natural conception

The worse outcome has been attributed to the higher frequency of multiple pregnancies and by confounding

\section{What this study adds}

Compared with non-assisted singleton pregnancies, singleton pregnancies from assisted conception have a significantly worse perinatal outcome

This is less so for twin pregnancies

In twin pregnancies, perinatal mortality is about $40 \%$ lower after assisted compared with natural conception

Results of the non-matched studies were similar

\section{Conclusions and recommendations}

Whatever the explanation may be, singletons from assisted conception are significantly disadvantaged compared with other singletons, but this is substantially less so for twins. Women undergoing assisted reproduction should be informed of the increased risks in singleton pregnancies. With a twin pregnancy they may be relatively advantaged compared with other twin gestations, but this is poor consolation for the much greater risks of twin pregnancy overall. Virtually all perinatal and infant morbidity occurs more frequently in twins than in singletons. ${ }^{3}$

Twenty five years after the birth of the first baby conceived by in vitro fertilisation, our data draw attention to three challenges. Firstly, emphasis needs to shift, more than it has already, ${ }^{32}$ from achieving pregnancy to achieving a successful outcome. Secondly, it may be timely to consider any multiple pregnancy after assisted conception as a failure of that technology to achieve what it ought to achieve. Thirdly, there is a need to narrow the gap in perinatal outcome between assisted and other singleton pregnancies. This may also enhance understanding of how gestational age, fetal growth, and birth weight interact with each other.

Contributors: FMH and MJNCK designed the review and its protocol. DAMP, DD, and MJNCK conducted the literature searches. DAMP and DD independently extracted data during separate study leaves at Flinders University. Disagreements were resolved in consultation with FMH and MJNCK, if necessary after clarification from the authors of the original studies. All authors contributed to earlier drafts of the manuscript, which was finalised by MJNCK. FMH and MJNCK are the guarantors.

Funding: Flinders University and Leiden University Medical Center.

Competing interests: None declared.

Ethical approval: Not needed.

1 Dhont M, De Sutter P, Ruyssinck G, Martens G, Bekaert A. Perinatal outcome of pregnancies after assisted reproduction: a case-control study. Am J Obstet Gynecol 1999;181:688-95.

2 Australian In Vitro Fertilisation Collaborative Group. High incidence of preterm births and early losses in pregnancy after in vitro fertilisation. BMJ 1985;291:1160-3.

3 Keirse MJNC, Helmerhorst FM. The impact of assisted reproduction on perinatal health care. Soz Präventiv Med 1995;40:343-51.

4 Tan SL, Doyle P, Campbell S, Beral V, Rizk B, Brinsden P, et al. Obstetric outcome of in vitro fertilization pregnancies compared with normally conceived pregnancies. Am J Obstet Gynecol 1992;167:778-84.

5 Tanbo T, Dale PO, Lunde O, Moe N, Abyholm T. Obstetric outcome in singleton pregnancies after assisted reproduction. Obstet Gynecol 1995;86:188-92.

6 Verlaenen H, Cammu H, Derde MP, Amy JJ. Singleton pregnancy after in vitro fertilization: expectations and outcome. Obstet Gynecol 1995;86:906-10.

7 Reubinoff BE, Samueloff A, Ben Haim M, Friedler S, Schenker JG, Lewin A. Is the Reubinoff BE, Samueloff A, Ben Haim M, Friedler S, Schenker JG, Lewin A. Is the
obstetric outcome of in vitro fertilized singleton gestations different from natural ones? A controlled study. Fertil Steril 1997;67:1077-83. 
8 Koudstaal J, Braat DD, Bruinse HW, Naaktgeboren N, Vermeiden JP, Visser GH Obstetric outcome of singleton pregnancies after IVF: a matched control study in fou Dutch university hospitals. Hum Reprod 2000;15:1819-25.

9 Dhont M, De Neubourg F, Van der Elst J, De Sutter P. Perinatal outcome of pregnancie after assisted reproduction: a case-control study. J Assist Reprod Genet 1997;14:575-80.

10 Isaksson R, Gissler M, Tiitinen A. Obstetric outcome among women with unexplained infertility after IVF: a matched case-control study. Hum Reprod 2002;17:1755-61.

11 Moise J, Laor A, Armon Y, Gur I, Gale R. The outcome of twin pregnancies after IVF. Hum Reprod 1998;13:1702-5.

12 Tallo CP, Vohr B, Oh W, Rubin LP, Seifer DB, Haning RV Jr. Maternal and neonatal morbidity associated with in vitro fertilization. J Pediatr 1995;127:794-800.

13 Koudstaal J, Bruinse HW, Helmerhorst FM, Vermeiden JP, Willemsen WN, Visser GH Obstetric outcome of twin pregnancies after in-vitro fertilization: a matched control study in four Dutch university hospitals. Hum Reprod 2000;15:935-40.

14 Agustsson T, Geirsson RT, Mires G. Obstetric outcome of natural and assisted concepion twin pregnancies is similar. Acta Obstet Gynecol Scand 1997;76:45-9

15 Minakami H, Sayama M, Honma Y, Matsubara S, Koike T, Sato I, et al. Lower risks of adverse outcome in twins conceived by artificial reproductive techniques compared with spontaneously conceived twins. Hum Reprod 1998;13:2005-8.

16 Fitzsimmons BP, Bebbington MW, Fluker MR. Perinatal and neonatal outcomes in multiple gestations: assisted reproduction versus spontaneous conception. Am J Obstel Gynecol 1998;179:1162-7.

17 Olivennes F, Kadhel P, Rufat P, Fanchin R, Fernandez H, Frydman R. Perinatal outcome of twin pregnancies obtained after in vitro fertilization: comparison with twin pregnanof twin pregnancies obtained after in vitro fertilization: comparison with twin pregnan-

18 D'Souza SW, Rivlin E, Cadman J, Richards B, Buck P, Lieberman BA. Children conceived by in vitro fertilisation after fresh embryo transfer. Arch Dis Child Fetal Neonatal Ed 1997:76:F70-4

19 Koivurova S, Hartikainen AL, Gissler M, Hemminki E, Sovio U, Jarvelin MR. Neonatal outcome and congenital malformations in children born after in-vitro fertilization. Hum Reprod 2002;17:1391-8

20 Maman E, Lunenfeld E, Levy A, Vardi H, Potashnik G. Obstetric outcome of singleton pregnancies conceived by in vitro fertilization and ovulation induction compared with those conceived spontaneously. Fertil Steril 1998;70:240-5.

21 Nuojua-Huttunen S, Gissler M, Martikainen H, Tuomivaara L. Obstetric and perinatal outcome of pregnancies after intrauterine insemination. Hum Reprod 1999;14:2 110-5.

22 Petersen K, Hornnes PJ, Ellingsen S, Jensen F, Brocks V, Starup J, et al. Perinatal Petersen K, Hornnes PJ, Ellingsen S, Jensen F, Brocks V, Starup J, et al.
outcome after in vitro fertilisation. Acta Obstet Gynecol Scand 1995;74:129-31.

23 Addor V, Santos-Eggimann B, Fawer CL, Paccaud F, Calame A. Impact of infertility reatments on the health of newborns. Fertil Steril 1998;69:210-5.

24 Frydman R, Belaisch-Allart J, Fries N, Hazout A, Glissant A, Testart J. An obstetric assessment of the first 100 births from the in vitro fertilization program at Clamart, France. Am J Obstet Gynecol 1986;154:550-5.
25 Olivennes F, Rufat P, Andre B, Pourade A, Quiros MC, Frydman R. The increased risk of complication observed in singleton pregnancies resulting from in-vitro fertilization IVF) does not seem to be related to the IVF method itself. Hum Reprod 1993;8:1297300.

26 Bernasko J, Lynch L, Lapinski R, Berkowitz RL. Twin pregnancies conceived by assisted reproductive techniques: maternal and neonatal outcomes. Obstet Gynecol 1997;89:36872 .

27 Daniel Y, Ochshorn Y, Fait G, Geva E, Bar-Am A, Lessing JB. Analysis of 104 twin pregnancies conceived with assisted reproductive technologies and 193 spontaneously conceived twin pregnancies. Fertil Steril 2000;74:683-9.

28 Lambalk CB, van Hooff M. Natural versus induced twinning and pregnancy outcome: a Dutch nationwide survey of primiparous dizygotic twin deliveries. Fertil Steri 2001;75:731-6.

29 Pandian Z, Bhattacharya S, Templeton A. Review of unexplained infertility and obstetric outcome: a 10 year review. Hum Reprod 2001;16:2593-7.

30 Keirse MJNC, Rush RW, Anderson ABM, Turnbull AC. Risk of pre-term delivery in patients with previous pre-term delivery and/or abortion. Br J Obstet Gynaecol 1978;85:81-5.

31 Keirse MJNC. International variations in intrauterine growth. Eur J Obstet Gynecol Reprod Biol 2000;92:21-8.

32 Nygren KG, Anderson AN. Assisted reproductive technology in Europe 1998. Results generated from European registers by ESHRE. Hum Reprod 2001;16:384-91.

33 Chow JS, Benson CB, Racowsky C, Doubilet PM, Ginsburg E. Frequency of a monochorionic pair in multiple gestations: relationship to mode of conception.J Ultra sound Med 2001;20:757-60.

(Accepted 13 November 2003)

doi 10.1136/bmj.37957.560278.EE

Department of Obstetrics, Gynaecology and Reproductive Medicine, Leiden University Medical Center, NL 2300 Leiden, Netherlands

Frans M Helmerhorst associated professor

Denise A M Perquin registrar

Diane Donker medical officer

Department of Obstetrics, Gynaecology and Reproductive Medicine, Flinders

University and Flinders Medical Centre, Adelaide, South Australia

Marc J N C Keirse professor

Correspondence to: F M Helmerhorst f.m.helmerhorst@lumc.nl 